\title{
Modelling and Analysis of Squirrel Cage Induction Motor with Leading Reactive Power Injection
}

\author{
Adisa A. Jimoh, Pierre-Jac Venter and Edward K. Appiah \\ Additional information is available at the end of the chapter
}

http://dx.doi.org/10.5772/50011

\section{Introduction}

Induction motors are by far the most used electro-mechanical device in industry today. Induction motors hold many advantages over other types of motors. They are cheap, rugged, easily maintainable and can be used in hazardous locations. Despite its advantages it has one major disadvantage. It draws reactive power from the source to be able to operate and therefore the power factor of the motor is inherently poor especially under starting conditions and under light load (Jimoh and Nicolae, 2007). Poor power factor adversely affects the economics of distribution and transmission systems and therefore may lead to higher electricity charges (Muljadi et al., 1989). At starting, power drawn by the motor is mainly reactive and it can draw up to 8 times its rated current at a power factor of about 0.2 until it reaches rated speed after which the power factor will increase to more than 0.6 if the motor is properly loaded and depending on the size of the motor.

To improve the power factor, reactive power compensation is needed where reactive power is injected. Several techniques have been suggested including synchronous compensation which is complex and expensive. Switched capacitor banks which requires expensive switchgear and may cause voltage regeneration, over voltage and high inrush currents (ElSharkawi et al., 1985).

In this chapter another approach for power factor correction is explored where the stator of an induction motor has two sets of three phase windings which is electrically isolated but magnetically coupled. The main winding is connected to the three phase supply and the auxiliary winding connected to fixed capacitors for reactive power injection.

The first part of this chapter focuses on the development of a mathematical model for a normal three phase induction motor, the second part of the chapter focuses on the 
development of the mathematical model for a dual winding three phase induction motor with reactive power injection, where the derived mathematical model is simulated using Matlab/Simulink environment and the third part of the chapter focuses on the performance analysis of both theoretical and experimental results.

\section{Arbitrary reference frame theory}

Arbitrary reference frame theory is mainly used in the dynamic analysis of electrical machines. Because of the highly coupled nature of the machine, especially the inductances within the winding make it rather impossible to perform dynamic simulations and analysis on electrical machines.

Arbitrary reference frame theory was discovered by Blondel, Dreyfus, Doherty and Nickle as mentioned in the classical paper (Park, 1929). This newly found theory was generalised by Park on synchronous machines and this method was later extended by Stanley to the application of dynamic analysis of induction machines (Stanley, 1938).

By using this method a poly-phase machine is transformed to a two-phase machine with their magnetic axis in quadrature as illustrated in Figure 1. This method is also commonly referred to as the $d q$ method in balanced systems and to the $d q 0$ method in unbalanced systems with the ' 0 'relating to the zero sequence or homopolar component in the Fortescue Transformation.

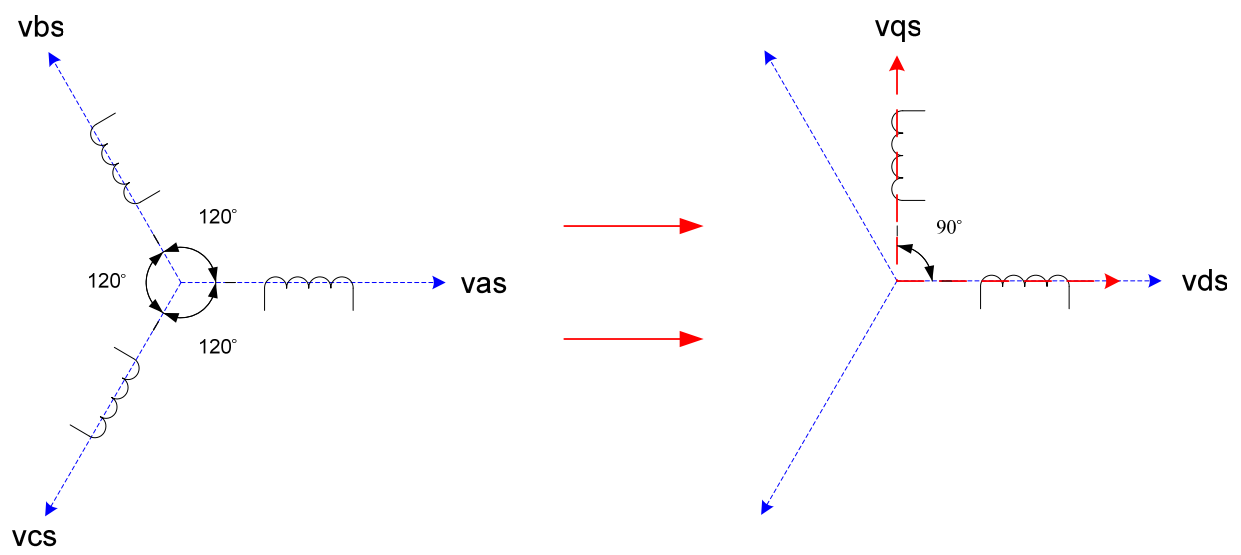

Figure 1. Park's Transform

This transformation eliminates mutual magnetic coupling between the phases and therefore makes the magnetic flux linkage of one winding independent of the current of another winding.

The transformation is done by applying a transformation matrix, Equation (1) while the inverse transformation matrix, Equation (2) will transform back to the natural reference frame. Equations (1)\&(2) applies to a three phase system but can be modified to 
accommodate a system with any number of phases which might be useful in the case of the machine having an auxiliary winding as proposed in this work.

$$
\begin{gathered}
{[C]=\frac{2}{3}\left[\begin{array}{ccc}
\cos \theta & \cos \left(\theta-\frac{2 \pi}{3}\right) & \cos \left(\theta-\frac{4 \pi}{3}\right) \\
\sin \theta & \sin \left(\theta-\frac{2 \pi}{3}\right) & \sin \left(\theta-\frac{4 \pi}{3}\right) \\
\frac{1}{2} & \frac{1}{2} & \frac{1}{2}
\end{array}\right]} \\
{[C]^{-1}=\left[\begin{array}{ccc}
\cos \theta & \sin \theta & 1 \\
\cos \left(\theta-\frac{2 \pi}{3}\right) & \sin \left(\theta-\frac{2 \pi}{3}\right) & 1 \\
\cos \left(\theta-\frac{4 \pi}{3}\right) & \sin \left(\theta-\frac{4 \pi}{3}\right) & 1
\end{array}\right]}
\end{gathered}
$$

\section{Modelling of three-phase induction motor}

The winding arrangement of a symmetrical induction machine is shown in Figure 2. The stator windings are identical and sinusoidally distributed, displaced $120^{\circ}$ apart, with $\mathrm{N}_{s}$ equivalent turns and resistance $r_{s}$ per winding per phase. Similarly the rotor windings are also considered as three identical sinusoidally distributed windings, displaced $120^{\circ}$ apart, with $\mathrm{N}_{\mathrm{r}}$ equivalent turns and resistance of $\mathrm{r}_{\mathrm{r}}$ per winding per phase.

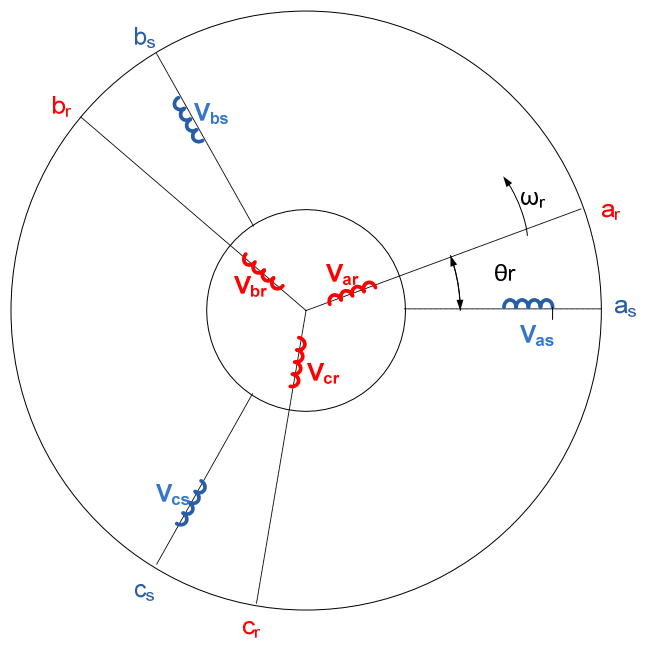

Figure 2. Three-Phase Winding Arrangement

In developing the equations which describe the behaviour of the induction machine the following assumptions are made:

1. The airgap is uniform.

2. Eddy currents, friction and windage losses and saturation are neglected.

3. The windings are distributed sinusoidally around the air gap.

4. The windings are identical 


\subsection{Voltage equations}

Using Kirchoff's Voltage Law, the voltage equations for each winding on the stator and rotor can be determined.

Stator Windings:

$$
\begin{aligned}
& v_{a s}=r_{s} i_{a s}+\frac{d \lambda_{a s}}{d t} \\
& v_{b s}=r_{s} i_{b s}+\frac{d \lambda_{b s}}{d t} \\
& v_{c s}=r_{s} i_{c s}+\frac{d \lambda_{c s}}{d t}
\end{aligned}
$$

Rotor Windings:

$$
\begin{aligned}
& v_{a r}=r_{r} i_{a r}+\frac{d \lambda_{a r}}{d t} \\
& v_{b r}=r_{r} i_{b r}+\frac{d \lambda_{b r}}{d t} \\
& v_{c r}=r_{r} i_{c r}+\frac{d \lambda_{c r}}{d t}
\end{aligned}
$$

With subscript ' $a$ ', ' $b$ ',' $c$ ' referring to the phases, subscript ' $s$ ' referring to stator variables, subscript ' $r$ ' referring to rotor variables, ' $v$ ' referring to instantaneous voltage, ' $i$ ' referring to instantaneous current and ' $\lambda$ ' referring to flux linkage.

After obtaining the voltage equations in the natural reference frame, the transformation to the arbitrary reference frame can be done. It is very convenient to first refer all rotor variables to the stator by applying the appropriate turns ratio. Equations (9)-(11) represents all rotor variables and is expressed in a simplified way including the variables of all the rotor phases in one equation.

$$
\begin{gathered}
i_{a b c r}^{\prime}=\frac{N_{r}}{N_{s}} i_{a b c r} \\
v_{a b c r}^{\prime}=\frac{N_{s}}{N_{r}} v_{a b c r} \\
\lambda^{\prime}{ }_{a b c r}=\frac{N_{s}}{N_{r}} \lambda_{a b c r}
\end{gathered}
$$

The transformation of the voltage equations to the arbitrary reference frame are dealt with in Section 3.3. It is important to determine the different inductances which will influence the flux linkage in Equations (3)-(8) and also transform it to the arbitrary reference frame.

\subsection{Inductances}

The flux linkages as seen in the voltage equations are functions of inductance and therefore the inductances within the motor must be determined. 
The inductances within the motor consist of self inductance, leakage inductance, magnetizing inductance and mutual inductance. The flux linkage equation is shown in Equation (12) and contains the inductance matrix [L].

$$
\left[\begin{array}{l}
\lambda_{a s} \\
\lambda_{b s} \\
\lambda_{c s} \\
\lambda_{a r} \\
\lambda_{b r} \\
\lambda_{c r}
\end{array}\right]=\left[\begin{array}{llllll}
L_{a s a s} & L_{a s b s} & L_{a s c s} & L_{a s a r} & L_{a s b r} & L_{a s c r} \\
L_{b s a s} & L_{b s b s} & L_{b s c s} & L_{b s a r} & L_{b s b r} & L_{b s c r} \\
L_{c s a s} & L_{c s b s} & L_{c s c s} & L_{c s a r} & L_{c s b r} & L_{c s c r} \\
L_{a r a s} & L_{a r b s} & L_{a r c s} & L_{a r a r} & L_{a r b r} & L_{a r c r} \\
L_{b r a s} & L_{b r b s} & L_{b r c s} & L_{b r a r} & L_{b r b r} & L_{b r c r} \\
L_{c r a s} & L_{c r b s} & L_{c r c s} & L_{c r a r} & L_{c r b r} & L_{c r c r}
\end{array}\right] \times\left[\begin{array}{c}
i_{a s} \\
i_{b s} \\
i_{c s} \\
i_{a r} \\
i_{b r} \\
i_{c r}
\end{array}\right]
$$

Where the inductance is defined by the subscript, for example Lasas refers to the inductance between winding as and winding as, meaning that this is self inductance in winding as; and Lasbr refers to the inductance between winding as and winding $b r$, meaning that this is a mutual inductance.

\subsubsection{Self inductance}

The self inductance in the stator windings consists of magnetizing and leakage inductance. The windings are identical and therefore the self inductance of all stator windings will be identical.

$$
L_{a s a s}=L_{b s b s}=L_{c s c s}=L_{m s}+L_{l s}
$$

The magnetizing inductance (Lms) can be expressed as in Equation (14) (Lipo and Novotny, 1996).

$$
L_{m s}=\frac{\mu_{0} \operatorname{lr} N_{s}^{2} \pi}{4 g}
$$

The self inductance in the rotor windings is similar to that of the stator windings.

$$
L_{\text {arar }}=L_{b r b r}=L_{c r c r}=L_{m r}+L_{l r}
$$

And,

$$
L_{m r}=\frac{\mu_{0} \ell r N_{r}^{2} \pi}{4 g}
$$

Where $N_{s}$ and $N_{r}$ is the effective number of turns of the stator and rotor windings, $r$ is the radius of the motor cross-section, $\ell$ is the length of the motor and $g$ is the airgap radial length.

\subsubsection{Mutual inductance}

Mutual inductance exists between all windings of both the stator and the rotor. There are four different types of mutual inductance which are stator-stator (mutual inductance between two different stator windings), rotor-rotor (mutual inductance between two different rotor windings), stator-rotor (mutual inductance between a stator and rotor winding) and rotor-stator (mutual inductance between a rotor and stator winding). 
Stator-stator mutual inductance can be expressed as Equation (17) (Lipo and Novotny, 1996).

$$
L_{x s y s}=\frac{\mu_{0} e r N_{s}^{2} \pi}{4 g} \cos \theta_{x s y s}
$$

Where Lxys is the inductance between any stator winding ' $x$ ' and any other stator winding ' $y$ ' and $\theta_{x s y s}$ is the angle between stator winding ' $x$ ' and ' $y$ '.

Using Equation (14), Equation (17) can be modified to be:

$$
L_{x s y s}=L_{m s} \cos \theta_{x s y s}
$$

When considering the winding distribution in Figure 2, it can be seen that the only possible displacement between two stator windings are $120^{\circ}$ and $240^{\circ}$ in both directions. This implies that $\cos \theta_{x s y s}$ in Equation (18) can be evaluated as follows:

$$
\cos \theta_{x s y s}=\cos \left( \pm 120^{\circ}\right)=\cos \left( \pm 240^{\circ}\right)=-\frac{1}{2}
$$

From Equations (18)\&(19) the expression describing the mutual inductance between any two stator windings can be simplified to Equation (20).

$$
L_{a s b s}=L_{a s c s}=L_{b s c s}=L_{b s a s}=L_{c s a s}=L_{c s b s}=-\frac{1}{2} L_{m s}
$$

The rotor-rotor mutual inductances are similar to that of the stator-stator mutual inductances and can be expressed as:

$$
L_{\text {arbr }}=L_{\text {arcr }}=L_{\text {brcr }}=L_{\text {brar }}=L_{\text {crar }}=L_{c r b r}=-\frac{1}{2} L_{m r}
$$

The stator-rotor mutual inductances depend on the position of the rotor according to the following relationship.

$$
L_{x s y r}=L_{s r} \cos \theta_{x s y r}
$$

Where $L_{x s y r}$ is the mutual inductance between any stator winding ' $x$ ' and any rotor winding ' $y$ '; and $\theta_{x s y r}$ is the angle between them.

The expression for $L_{s r}$ in Equation (22) is given by Equation (23).

$$
L_{s r}=\left(\frac{N_{s}}{2}\right)\left(\frac{N_{r}}{2}\right) \frac{\mu_{0} \pi r \ell}{g}
$$

(Krause, 1986, Lipo and Novotny, 1996)

Now, using Equation (22) and Figure 2, the expressions for the stator-rotor mutual inductances can be deduced.

$$
\begin{gathered}
L_{a s a r}=L_{b s b r}=L_{c s c r}=L_{s r} \cos \theta_{r} \\
L_{a s b r}=L_{b s c r}=L_{c s a r}=L_{s r} \cos \left(\theta_{r}+\frac{2 \pi}{3}\right)
\end{gathered}
$$




$$
L_{a s c r}=L_{b s a r}=L_{c s b r}=L_{s r} \cos \left(\theta_{r}-\frac{2 \pi}{3}\right)
$$

Likewise it can be shown that the rotor-stator mutual inductances are:

$$
\begin{gathered}
L_{\text {aras }}=L_{\text {brbs }}=L_{c r c s}=L_{s r} \cos \left(-\theta_{r}\right) \\
L_{\text {arbs }}=L_{\text {brcs }}=L_{c r a s}=L_{s r} \cos \left(\frac{2 \pi}{3}-\theta_{r}\right) \\
L_{\text {arcs }}=L_{\text {bras }}=L_{c r b s}=L_{s r} \cos \left(\frac{4 \pi}{3}-\theta_{r}\right)
\end{gathered}
$$

All inductances have now been quantified. The complete inductance matrix can now be constructed but to simplify the work the inductance matrix in Equation (12) is first divided into sub-matrices. The inductance matrix as in Equation (12) is repeated as Equation (30).

$$
L=\left[\begin{array}{llllll}
L_{\text {asas }} & L_{\text {asbs }} & L_{\text {ascs }} & L_{\text {asar }} & L_{\text {asbr }} & L_{\text {ascr }} \\
L_{\text {bsas }} & L_{\text {bsbs }} & L_{\text {bscs }} & L_{\text {bsar }} & L_{\text {bsbr }} & L_{\text {bscr }} \\
L_{\text {csas }} & L_{c s b s} & L_{c s c s} & L_{c s a r} & L_{c s b r} & L_{c s c r} \\
L_{\text {aras }} & L_{\text {arbs }} & L_{\text {arcs }} & L_{\text {arar }} & L_{a r b r} & L_{\text {arcr }} \\
L_{\text {bras }} & L_{\text {brbs }} & L_{\text {brcs }} & L_{\text {brar }} & L_{b r b r} & L_{\text {brcr }} \\
L_{\text {cras }} & L_{\text {crbs }} & L_{\text {crcs }} & L_{\text {crar }} & L_{c r b r} & L_{\text {crcr }}
\end{array}\right]
$$

The inductance matrix is divided into four sub-matrices.

$$
L=\left[\begin{array}{cc}
L_{S} & L_{S R} \\
L_{R S} & L_{r}
\end{array}\right]
$$

Where $L_{s}$ is the inductance within the stator windings, $L_{r}$ is the inductances within the rotor windings, $L_{S R}$ is the inductances between stator and rotor windings and $L_{R S}$ is the inductances between the rotor and stator windings.

Using Equation (30) and dividing according to Equation (31) and substituting inductances yield the following:

$$
\begin{gathered}
L_{s}=\left[\begin{array}{ccc}
L_{m s}+L_{l s} & -\frac{1}{2} L_{m s} & -\frac{1}{2} L_{m s} \\
-\frac{1}{2} L_{m s} & L_{m s}+L_{l s} & -\frac{1}{2} L_{m s} \\
-\frac{1}{2} L_{m s} & -\frac{1}{2} L_{m s} & L_{m s}+L_{l s}
\end{array}\right] \\
L_{r}=\left[\begin{array}{ccc}
L_{m r}+L_{l r} & -\frac{1}{2} L_{m r} & -\frac{1}{2} L_{m r} \\
-\frac{1}{2} L_{m r} & L_{m r}+L_{l r} & -\frac{1}{2} L_{m r} \\
-\frac{1}{2} L_{m r} & -\frac{1}{2} L_{m r} & L_{m r}+L_{l r}
\end{array}\right] \\
L_{S R}=L_{s r}\left[\begin{array}{ccc}
\cos \theta_{r} & \cos \left(\theta_{r}+\frac{2 \pi}{3}\right) & \cos \left(\theta_{r}-\frac{2 \pi}{3}\right) \\
\cos \left(\theta_{r}-\frac{2 \pi}{3}\right) & \cos \theta_{r} & \cos \left(\theta_{r}+\frac{2 \pi}{3}\right) \\
\cos \left(\theta_{r}+\frac{2 \pi}{3}\right) & \cos \left(\theta_{r}-\frac{2 \pi}{3}\right) & \cos \theta_{r}
\end{array}\right]
\end{gathered}
$$




$$
L_{R S=}\left(L_{S R}\right)^{T}=L_{S r}\left[\begin{array}{ccc}
\cos \theta_{r} & \cos \left(\theta_{r}-\frac{2 \pi}{3}\right) & \cos \left(\theta_{r}+\frac{2 \pi}{3}\right) \\
\cos \left(\theta_{r}+\frac{2 \pi}{3}\right) & \cos \theta_{r} & \cos \left(\theta_{r}-\frac{2 \pi}{3}\right) \\
\cos \left(\theta_{r}-\frac{2 \pi}{3}\right) & \cos \left(\theta_{r}+\frac{2 \pi}{3}\right) & \cos \theta_{r}
\end{array}\right]
$$

It can be proven that $L_{R S=}\left(L_{S R}\right)^{T}$.

It is evident that $\theta_{r}$ exists in Equations (34)\&(35) where $\theta_{r}$ relates to rotor position, this rotor position changes continuously which means that in the natural state the inductances are varying with time. To be able to derive a rigorous dynamic model de-coupling has to be done by using arbitrary reference frame theory as mentioned in Section 2.

Before transforming the inductances to the arbitrary reference frame all rotor parameters must be referred to the stator.

The magnetizing inductances $\left(L_{m s}, L_{m r}\right)$ and mutual inductances $\left(L_{s r}, L_{r s}\right)$ are from the same magnetic flux path and are therefore related. From Equations (14)\&(23) it can be deduced that:

$$
L_{m s}=\left(\frac{N_{s}}{N_{r}}\right) L_{s r}
$$

By using the effective turns ratio $L_{s r}$ can be referred to the stator.

$$
L_{s r}^{\prime}=\frac{N_{s}}{N_{r}}\left(L_{s r}\right)
$$

And therefore

$$
L_{s r}^{\prime}=L_{m s}
$$

The mutual inductance matrix referred to the stator can now be expressed as:

$$
L_{S R}^{\prime}=L_{m s}\left[\begin{array}{ccc}
\cos \theta_{r} & \cos \left(\theta_{r}+\frac{2 \pi}{3}\right) & \cos \left(\theta_{r}-\frac{2 \pi}{3}\right) \\
\cos \left(\theta_{r}-\frac{2 \pi}{3}\right) & \cos \theta_{r} & \cos \left(\theta_{r}+\frac{2 \pi}{3}\right) \\
\cos \left(\theta_{r}+\frac{2 \pi}{3}\right) & \cos \left(\theta_{r}-\frac{2 \pi}{3}\right) & \cos \theta_{r}
\end{array}\right]
$$

Using the same approach the inductances within the rotor windings can also be simplified as:

$$
L_{r}^{\prime}=\left[\begin{array}{ccc}
L^{\prime}{ }_{l r}+L_{m s} & -\frac{1}{2} L_{m s} & -\frac{1}{2} L_{m s} \\
-\frac{1}{2} L_{m s} & L^{\prime}{ }_{l r}+L_{m s} & -\frac{1}{2} L_{m s} \\
-\frac{1}{2} L_{m s} & -\frac{1}{2} L_{m s} & L_{l r}^{\prime}+L_{m s}
\end{array}\right]
$$

The flux linkage can now be expressed as:

$$
\left[\begin{array}{c}
\lambda_{a b c s} \\
\lambda^{\prime}{ }_{a b c r}
\end{array}\right]=\left[\begin{array}{cc}
L_{s} & L_{S R}^{\prime} \\
\left(L_{S R}^{\prime}\right)^{T} & L_{r}^{\prime}
\end{array}\right] \times\left[\begin{array}{c}
i_{a b c s} \\
i^{\prime}{ }_{a b c r}
\end{array}\right]
$$

Equation (41) can be transformed to the arbitrary reference frame as indicated in Equation (42) (Krause, 1986). 


$$
\left[\begin{array}{l}
\lambda_{\text {qd0s }} \\
\lambda^{\prime}{ }_{\text {qdor }}
\end{array}\right]=\left[\begin{array}{cc}
K_{S} L_{s} K_{S}{ }^{-1} & K_{S} L_{S R}^{\prime} K_{r}^{-1} \\
K_{r}\left(L_{S R}^{\prime}\right)^{T} K_{S}^{-1} & K_{r} L_{r}^{\prime} K_{r}{ }^{-1}
\end{array}\right] \times\left[\begin{array}{c}
i_{q d 0 s} \\
i_{\text {qdor }}^{\prime}
\end{array}\right]
$$

Where;

$$
\begin{gathered}
K_{s}=\frac{2}{3}\left[\begin{array}{ccc}
\cos \theta & \cos \left(\theta-\frac{2 \pi}{3}\right) & \cos \left(\theta-\frac{4 \pi}{3}\right) \\
\sin \theta & \sin \left(\theta-\frac{2 \pi}{3}\right) & \sin \left(\theta-\frac{4 \pi}{3}\right) \\
\frac{1}{2} & \frac{1}{2} & \frac{1}{2}
\end{array}\right] \\
K_{s}^{-1}=\left[\begin{array}{ccc}
\cos \theta & \sin \theta & 1 \\
\cos \left(\theta-\frac{2 \pi}{3}\right) & \sin \left(\theta-\frac{2 \pi}{3}\right) & 1 \\
\cos \left(\theta-\frac{4 \pi}{3}\right) & \sin \left(\theta-\frac{4 \pi}{3}\right) & 1
\end{array}\right] \\
K_{r}=\frac{2}{3}\left[\begin{array}{cccc}
\cos \beta & \cos \left(\beta-\frac{2 \pi}{3}\right) & \cos \left(\beta-\frac{4 \pi}{3}\right) \\
\sin \beta & \sin \left(\beta-\frac{2 \pi}{3}\right) & \sin \left(\beta-\frac{4 \pi}{3}\right) \\
\frac{1}{2} & \frac{1}{2} & \frac{1}{2}
\end{array}\right] \\
K_{r}^{-1}=\left[\begin{array}{llll}
\cos \beta & \sin \beta & 1 \\
\cos \left(\beta-\frac{2 \pi}{3}\right) & \sin \left(\beta-\frac{2 \pi}{3}\right) & 1 \\
\cos \left(\beta-\frac{4 \pi}{3}\right) & \sin \left(\beta-\frac{4 \pi}{3}\right) & 1
\end{array}\right]
\end{gathered}
$$

Where;

$$
\beta=\theta-\theta_{r}
$$

$K_{S}$ is the transformation matrix and $K_{S}^{-1}$ the inverse transformation matrix for the stator parameters, $K_{r}$ is the transformation matrix and $K_{r}^{-1}$ the inverse transformation matrix for the rotor parameters.

Evaluating Equation (42) with Equations (43)-(46) yield the flux linkage in the arbitrary reference frame as shown in Equation (48).

Comparing Equation (48) with Equations (32)-(35), it is clear that $\theta_{r}$ has been eliminated from the flux linkage equations by using the arbitrary reference frame transformation. It means that the flux linkage is no longer a function of rotor position.

$$
\left[\begin{array}{c}
\lambda_{q s} \\
\lambda_{d s} \\
\lambda_{0 s} \\
\lambda^{\prime}{ }_{q r} \\
\lambda^{\prime}{ }_{d r} \\
\lambda^{\prime}{ }_{0 r}
\end{array}\right]=\left[\begin{array}{cccccc}
L_{l s}+\frac{3}{2} L_{m s} & 0 & 0 & \frac{3}{2} L_{m s} & 0 & 0 \\
0 & L_{l s}+\frac{3}{2} L_{m s} & 0 & 0 & \frac{3}{2} L_{m s} & 0 \\
0 & 0 & L_{l s} & 0 & 0 & 0 \\
\frac{3}{2} L_{m s} & 0 & 0 & L_{l r}^{\prime}+\frac{3}{2} L_{m s} & 0 & 0 \\
0 & \frac{3}{2} L_{m s} & 0 & 0 & L_{l r}^{\prime}+\frac{3}{2} L_{m s} & 0 \\
0 & 0 & 0 & 0 & 0 & L^{\prime}{ }_{l r}
\end{array}\right] \times\left[\begin{array}{c}
i_{q s} \\
i_{d s} \\
i_{0 s} \\
i_{q r}^{\prime} \\
i^{\prime} d r \\
i_{0 r}^{\prime}
\end{array}\right]
$$




$$
L_{m}=\frac{3}{2} L_{m s}
$$

\subsection{Voltage equations in arbitrary reference frame}

Recalling and repeating the voltage equations in the natural reference frame in section 3.1, for ease of reading only, now it is presented in matrix format.

$$
\begin{gathered}
v_{a b c s}=r_{s} i_{a b c s}+\frac{d \lambda_{a b c s}}{d t} \\
v^{\prime}{ }_{a b c r}=r^{\prime}{ }_{r} i^{\prime}{ }_{a b c r}+\frac{d \lambda_{a b c r}}{d t}
\end{gathered}
$$

Taking only the stator voltage equations as in Equation (50) and only considering the resistive part, it can be transformed to the arbitrary reference frame as follows:

$$
\begin{gathered}
v_{q d 0 s}^{r e s}=K_{s} r_{s} K_{s}^{-1} i_{q d 0 s} \\
K_{s} r_{s} K_{s}^{-1}=\left[\begin{array}{ccc}
r_{s} & 0 & 0 \\
0 & r_{s} & 0 \\
0 & 0 & r_{s}
\end{array}\right]
\end{gathered}
$$

Therefore;

$$
v_{q d 0 s}^{r e s}=r_{s} i_{q d 0 s}
$$

Where;

$$
r_{s}=\left[\begin{array}{ccc}
r_{s} & 0 & 0 \\
0 & r_{s} & 0 \\
0 & 0 & r_{s}
\end{array}\right]
$$

The superscript 'res' refers to the resistive part of the voltage equation.

Now considering only the inductive part of the of the voltage equation as in Equation (50) which can be transformed to the arbitrary reference frame as follows:

$$
v_{q d 0 s}^{\text {ind }}=K_{s} \frac{d}{d t}\left[K_{s}^{-1} \lambda_{q d 0 s}\right]
$$

Expanding Equation (56) using the product rule:

$$
v_{q d 0 s}^{i n d}=K_{s} \frac{d}{d t}\left[K_{s}^{-1}\right] \lambda_{q d 0 s}+K_{s} K_{s}^{-1} \frac{d}{d t} \lambda_{q d 0 s}
$$

Now, evaluating parts of the terms in Equation (57) separately;

Knowing that;

$$
\theta=\int \omega(\xi) d \xi+\theta(0)
$$


Where $\xi$ is a dummy variable for integration.

$$
\begin{gathered}
\frac{d}{d t}\left[K_{s}^{-1}\right]=\omega\left[\begin{array}{ccc}
-\sin \theta & \cos \theta & 0 \\
-\sin \left(\theta-\frac{2 \pi}{3}\right) & \cos \left(\theta-\frac{2 \pi}{3}\right) & 0 \\
-\sin \left(\theta+\frac{2 \pi}{3}\right) & \cos \left(\theta+\frac{2 \pi}{3}\right) & 0
\end{array}\right] \\
K_{s} \frac{d}{d t}\left[K_{s}^{-1}\right]=\left[\begin{array}{ccc}
0 & \omega & 0 \\
-\omega & 0 & 0 \\
0 & 0 & 0
\end{array}\right] \\
K_{S} K_{s}^{-1}=\left[\begin{array}{lll}
1 & 0 & 0 \\
0 & 1 & 0 \\
0 & 0 & 1
\end{array}\right]
\end{gathered}
$$

Using Equations (58)-(61) to evaluate Equation (57) yields;

$$
v_{q d 0 s}^{\text {ind }}=\omega\left[\begin{array}{c}
\lambda_{d s} \\
-\lambda_{q s} \\
0
\end{array}\right]+\frac{d}{d t}\left[\begin{array}{c}
\lambda_{q s} \\
\lambda_{d s} \\
\lambda_{0 s}
\end{array}\right]
$$

The superscript 'ind' refers to the inductive part of the voltage equation.

Now adding the voltage equations for the resistive and inductive parts gives the full stator voltage equations in the arbitrary reference frame.

$$
v_{q d 0 s}=\left[\begin{array}{ccc}
r_{s} & 0 & 0 \\
0 & r_{s} & 0 \\
0 & 0 & r_{s}
\end{array}\right]\left[\begin{array}{c}
i_{q s} \\
i_{d s} \\
i_{0}
\end{array}\right]+\omega\left[\begin{array}{c}
\lambda_{d s} \\
-\lambda_{q s} \\
0
\end{array}\right]+\frac{d}{d t}\left[\begin{array}{c}
\lambda_{q s} \\
\lambda_{d s} \\
\lambda_{0 s}
\end{array}\right]
$$

Using the same method the rotor voltage equation can be determined.

$$
v_{q d 0 r}^{\prime}=\left[\begin{array}{ccc}
r_{r}^{\prime} & 0 & 0 \\
0 & r_{r}^{\prime} & 0 \\
0 & 0 & r_{r}^{\prime}
\end{array}\right]\left[\begin{array}{c}
i^{\prime}{ }_{q r} \\
i_{d r}^{\prime} \\
i_{0 r}^{\prime}
\end{array}\right]+\left(\omega-\omega_{r}\right)\left[\begin{array}{c}
\lambda^{\prime}{ }_{d r} \\
-\lambda_{q r}^{\prime} \\
0
\end{array}\right]+\frac{d}{d t}\left[\begin{array}{c}
\lambda^{\prime}{ }_{q r} \\
\lambda^{\prime}{ }_{d r} \\
\lambda_{0 r}
\end{array}\right]
$$

Where $\omega$ is the rotational speed of the reference frame and $\omega_{r}$ is the rotational speed of the rotor.

The model developed up to now is a general model in the arbitrary reference frame which means that this model can take the form of any reference frame depending the value substituted for $\omega$, therefore called arbitrary.

Different reference frames are obtained by substituting the appropriate value of the reference frame speed into $\omega$. Three different reference frames are commonly used, the stationary reference frame where $\omega=0$, the synchronous reference frame where $\omega$ is set to the angular velocity of the supply voltage $\left(\omega=\omega_{e}\right)$ and the rotor reference frame where $\omega$ is set to the angular velocity of the rotor $\left(\omega=\omega_{r}\right)$. The use of reference frames depends on the nature of the problem to be solved. 


\subsection{Electromagnetic torque}

The torque equation for a three phase induction machine is well known and is not derived in this section. The torque equation of the three phase machine with auxiliary winding is derived in Section 4.

$$
T_{e}=\left(\frac{3}{2}\right)\left(\frac{P}{2}\right)\left(\lambda_{d s} i_{q s}-\lambda_{q s} i_{d s}\right)
$$

An electric motor is an electro-mechanical device and needs an equation that couples the electrical and mechanical systems.

$$
T_{e m}=J\left(\frac{2}{P}\right) \frac{d \omega_{r}}{d t}+T_{L}
$$

Where $\mathrm{P}$ is number of poles, $\mathrm{J}$ is moment of inertia, $\mathrm{T}_{\mathrm{L}}$ is torque connected to the shaft and $\omega_{r}$ is the angular rotational speed of the rotor.

\subsection{Equivalent circuit}

The full mathematical model of the three phase induction machine is given by Equations (48),(63)\&(64). These equations are used to develop the equivalent circuits for the three phase induction machine as in Figure 3

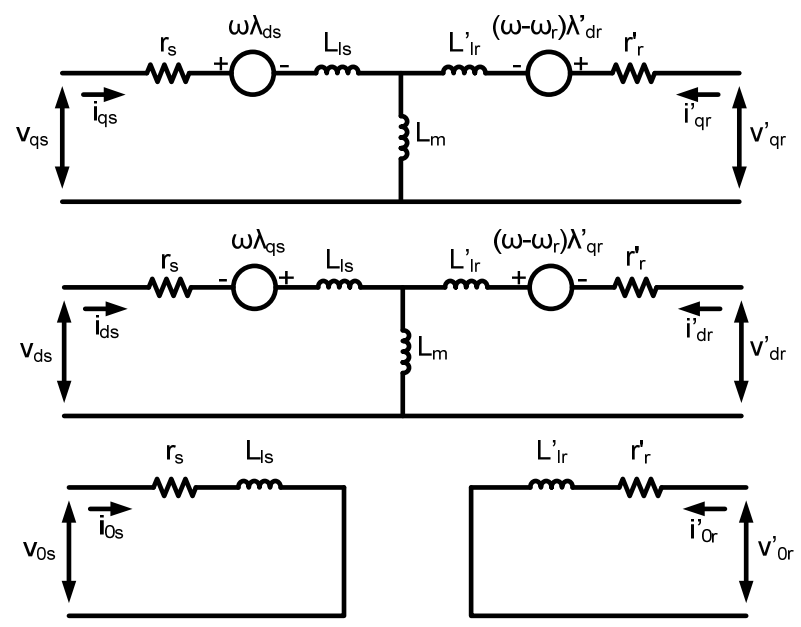

Figure 3. Equivalent Circuits

\section{Modelling of three-phase with auxiliary winding}

This machine consists of two three phase windings arranged on top of each other in the same slots. This means that there is no displacement between the two windings. These two windings are electrically isolated but magnetically connected. One of these windings is treated as the main winding and will be supplied with a three phase voltage. The main 
winding is labelled with the subscript ' $a b c^{\prime}$. The remaining winding is treated as the auxiliary winding. The auxiliary winding is connected to static capacitors for reactive power injection. The injection of reactive power will improve the power factor of the machine. The auxiliary winding is labelled with the subscript ' $x y z$ '. The winding arrangement is as shown in Figure 4.

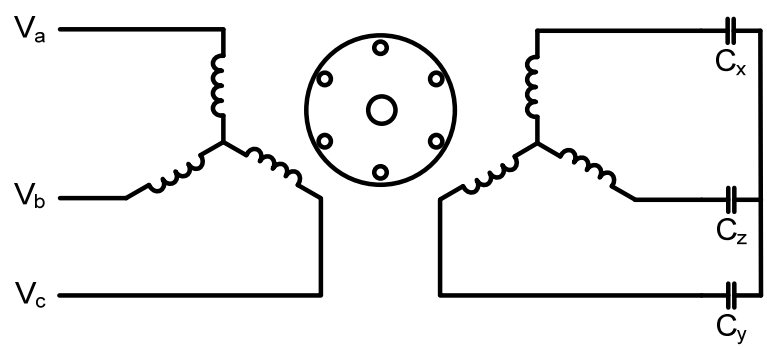

Figure 4. Winding arrangement of Main and Auxiliary Windings

The assumptions in developing the equations which describe the behaviour of this machine are the same as the assumptions mentioned in Section 3 with one addition. It is assumed that the main and auxiliary winding is identical. It has the same conductor cross section and the same number of turns.

\subsection{Voltage equations}

The voltage equations for this machine are developed in the same way as described in Section 3.1. There are three additional voltage equations because of the additional set of three phase windings. For simplicity the voltage equations are represented in matrix format. It is assumed that the main and auxiliary windings are identical and will therefore have the same resistance.

Main Stator Windings:

$$
v_{a b c s}=r_{s} i_{a b c s}+\frac{d \lambda_{a b c s}}{d t}
$$

Auxiliary Stator Windings:

$$
v_{x y z s}=r_{s} i_{x y z s}+\frac{d \lambda_{x y z s}}{d t}
$$

Rotor Windings:

$$
v_{a b c r}^{\prime}=r_{r}^{\prime} i_{a b c r}^{\prime}+\frac{d \lambda_{a b c r}}{d t}
$$

\subsection{Inductances}

Because of the addition of the auxiliary winding the dimensions of the inductance matrix will increase. The dimension of the inductance matrix is equal to the number of windings, in 
this case a [9 $\times 9$ ] matrix. The inductance matrix can again be divided into smaller more manageable sub-matrices as in Equation (70).

$$
\left[\begin{array}{c}
L_{a b c_{-} s} \\
L_{x y z_{-} s} \\
L_{a b c_{-} r}
\end{array}\right]=\left[\begin{array}{ccc}
L_{a b c s} & L_{a b c s x y z s} & L_{a b c s a b c r} \\
L_{x y z s a b c s} & L_{x y z s} & L_{x y z s a b c r} \\
L_{a b c r a b c s} & L_{a b c r x y z s} & L_{a b c r}
\end{array}\right]
$$

where Labcs, Lxyzs, Labcr are the inductances within the different three phase sets of windings. The other sub-matrices refer to mutual inductances between different sets of windings. This includes stator and rotor windings, for example Labcsxyzs refer to the mutual inductance between the main winding and the auxiliary winding on the stator. Many of the inductances in this structure are very similar to that of the conventional three phase machine. Therefore, many of the developed inductances in Section 3 can be used.

$$
\begin{gathered}
L_{a b c s}=L_{x y z s}=\left[\begin{array}{ccc}
L_{m s}+L_{l s} & -\frac{1}{2} L_{m s} & -\frac{1}{2} L_{m s} \\
-\frac{1}{2} L_{m s} & L_{m s}+L_{l s} & -\frac{1}{2} L_{m s} \\
-\frac{1}{2} L_{m s} & -\frac{1}{2} L_{m s} & L_{m s}+L_{l s}
\end{array}\right] \\
L_{a b c r}=\left[\begin{array}{ccc}
L_{m r}+L_{l r} & -\frac{1}{2} L_{m r} & -\frac{1}{2} L_{m r} \\
-\frac{1}{2} L_{m r} & L_{m r}+L_{l r} & -\frac{1}{2} L_{m r} \\
-\frac{1}{2} L_{m r} & -\frac{1}{2} L_{m r} & L_{m r}+L_{l r}
\end{array}\right] \\
L_{a b c s a b c r}=L_{x y z s a b c r}=L_{m s}\left[\begin{array}{ccc}
\cos \theta_{r} & \cos \left(\theta_{r}+\frac{2 \pi}{3}\right) & \cos \left(\theta_{r}-\frac{2 \pi}{3}\right) \\
\cos \left(\theta_{r}-\frac{2 \pi}{3}\right) & \cos \theta_{r} & \cos \left(\theta_{r}+\frac{2 \pi}{3}\right) \\
\cos \left(\theta_{r}+\frac{2 \pi}{3}\right) & \cos \left(\theta_{r}-\frac{2 \pi}{3}\right) & \cos \theta_{r}
\end{array}\right] \\
L_{a b c r a b c s}=L_{a b c r x y z s}=L_{a b c s a b c r}^{T}
\end{gathered}
$$

All of the above was taken from Section 3 because of similar relationships between the windings. The only sub-matrices remaining are the two describing the inductances between the main and auxiliary windings on the stator. For determining the expressions of all the elements of the sub-matrices, equation (18) is used.

$$
L_{\text {abcsxyzs }}=\left[\begin{array}{lll}
L_{a s x s} & L_{a s y s} & L_{a s z s} \\
L_{b s x s} & L_{b s y s} & L_{b s z s} \\
L_{c s x s} & L_{c s y s} & L_{c s z s}
\end{array}\right]
$$

Where;

$$
\begin{gathered}
L_{a s x s}=L_{b s y s}=L_{c s z s}=L_{m s} \cos \left(0^{\circ}\right)=L_{m s} \\
L_{a s y s}=L_{a s z s}=L_{b s x s}=L_{b s z s}=L_{c s x s}=L_{c s z s}=L_{m s} \cos \left( \pm 120^{\circ}\right)=-\frac{1}{2} L_{m s}
\end{gathered}
$$

Now; 


$$
L_{\text {abcsxyzs }}=\left[\begin{array}{ccc}
L_{m s} & -\frac{1}{2} L_{m s} & -\frac{1}{2} L_{m s} \\
-\frac{1}{2} L_{m s} & L_{m s} & -\frac{1}{2} L_{m s} \\
-\frac{1}{2} L_{m s} & -\frac{1}{2} L_{m s} & L_{m s}
\end{array}\right]
$$

It can be shown that;

$$
L_{x y z s a b c s}=L_{a b c s x y z s}
$$

Mutual leakage inductance exists between the main and auxiliary windings because they are sharing the same stator slots. This mutual leakage inductance should be reflected in Equation (78) but are neglected for the purpose of this study.

Transforming the inductance matrix in the natural reference frame to the arbitrary reference frame as explained in Section 3.2 yields the following inductance matrix in the arbitrary reference frame.

$$
\left[\begin{array}{l}
L_{q 1 s} \\
L_{d 1 s} \\
L_{01 s} \\
L_{q 2 s} \\
L_{d 2 s} \\
L_{02 s} \\
L_{q r} \\
L_{d r} \\
L_{0 r}
\end{array}\right]=\left[\begin{array}{ccccccccc}
L_{s s} & 0 & 0 & L_{m} & 0 & 0 & L_{m} & 0 & 0 \\
0 & L_{s s} & 0 & 0 & L_{m} & 0 & 0 & L_{m} & 0 \\
0 & 0 & L_{l s} & 0 & 0 & 0 & 0 & 0 & 0 \\
L_{m} & 0 & 0 & L_{s s} & 0 & 0 & L_{m} & 0 & 0 \\
0 & L_{m} & 0 & 0 & L_{s s} & 0 & 0 & L_{m} & 0 \\
0 & 0 & 0 & 0 & 0 & L_{l s} & 0 & 0 & 0 \\
L_{m} & 0 & 0 & L_{m} & 0 & 0 & L_{r r} & 0 & 0 \\
0 & L_{m} & 0 & 0 & L_{m} & 0 & 0 & L_{r r} & 0 \\
0 & 0 & 0 & 0 & 0 & 0 & 0 & 0 & L_{l r}^{\prime}
\end{array}\right]
$$

Where;

$$
\begin{aligned}
& L_{s s}=L_{l s}+L_{m} \\
& L_{r r}=L_{l r}^{\prime}+L_{m}
\end{aligned}
$$

Where the subscripts ' 1 ' refers to the main stator winding, ' 2 ' refers to the auxiliary stator winding and ' $r$ ' refers to the rotor winding.

Because flux linkage appears in the voltage equations it is very convenient to represent flux linkage instead of inductance.

$$
\lambda=\boldsymbol{L I}
$$

Where Equation (83) is in matrix format and refers to any flux linkage in the system.

\subsection{Voltage equation in the arbitrary reference frame}

The voltage equations as developed in Section 4.1 can be transformed to the arbitrary reference frame. This is quite an easy task when the developments in Section 3 are used. The equation for the main winding on the stator and the rotor winding remains the same as that for the conventional three-phase machine as shown in Equations (84)-(85). 


$$
\begin{gathered}
v_{q d 01 s}=\left[\begin{array}{ccc}
r_{s} & 0 & 0 \\
0 & r_{s} & 0 \\
0 & 0 & r_{s}
\end{array}\right]\left[\begin{array}{l}
i_{q 1 s} \\
i_{d 1 s} \\
i_{01 s}
\end{array}\right]+\omega\left[\begin{array}{c}
\lambda_{d 1 s} \\
-\lambda_{q 1 s} \\
0
\end{array}\right]+\frac{d}{d t}\left[\begin{array}{c}
\lambda_{q 1 s} \\
\lambda_{d 1 s} \\
\lambda_{01 s}
\end{array}\right] \\
v^{\prime}{ }_{q d 0 r}=\left[\begin{array}{ccc}
r_{r}^{\prime} & 0 & 0 \\
0 & r_{r}^{\prime} & 0 \\
0 & 0 & r^{\prime}{ }_{r}
\end{array}\right]\left[\begin{array}{c}
i^{\prime}{ }_{q r} \\
i^{\prime} \\
i^{\prime}{ }_{0 r}
\end{array}\right]+\left(\omega-\omega_{r}\right)\left[\begin{array}{c}
\lambda^{\prime}{ }_{d r} \\
-\lambda^{\prime}{ }_{q r} \\
0
\end{array}\right]+\frac{d}{d t}\left[\begin{array}{c}
\lambda^{\prime}{ }_{q r} \\
\lambda^{\prime} \\
\lambda_{0 r}
\end{array}\right]
\end{gathered}
$$

The voltage equations of the auxiliary winding are different from the main winding because no voltage is applied directly to the winding. Capacitors are rather connected to the auxiliary winding as in Figure 4. It is therefore important to develop the voltage equation for a capacitor in the arbitrary reference frame. This is given in Equation (86).

$$
V c_{q d 02 s}=\frac{1}{C} \int\left[i_{q d 0 s 2}\right] d t+\omega\left[\begin{array}{c}
V c_{d 02} \\
-V c_{q 02} \\
0
\end{array}\right]
$$

Now, the voltage equation for the auxiliary winding becomes;

$$
v_{q d 02 s}=0=\left[\begin{array}{ccc}
r_{s} & 0 & 0 \\
0 & r_{s} & 0 \\
0 & 0 & r_{s}
\end{array}\right]\left[\begin{array}{l}
i_{q 2 s} \\
i_{d 2 s} \\
i_{02 s}
\end{array}\right]+\omega\left[\begin{array}{c}
\lambda_{d 2 s} \\
-\lambda_{q 2 s} \\
0
\end{array}\right]+\frac{d}{d t}\left[\begin{array}{c}
\lambda_{q 2 s} \\
\lambda_{d 2 s} \\
\lambda_{02 s}
\end{array}\right]+\left[\begin{array}{c}
V c_{q 2} \\
V c_{d 2} \\
0
\end{array}\right]
$$

\subsection{Electromagnetic torque}

The electromagnetic torque can be derived from the energy stored in the coupling system. The stored energy for a normal three-phase can be written as Equation (88) (Krause, 1986).

$$
W_{f}=\frac{1}{2}\left(i_{a b c s}\right)^{T}\left(L_{s}-L_{l s} I\right) i_{a b c s}+\left(i_{a b c s}\right)^{T} L_{s r}^{\prime} i^{\prime}{ }_{a b c r}+\frac{1}{2}\left(i^{\prime}{ }_{a b c r}\right)^{T}\left(L_{r}^{\prime}-L^{\prime}{ }_{l r} I\right) i^{\prime}{ }_{a b c r}
$$

Where I is the identity matrix. The machine is assumed to be magnetically linear and therefore, the field energy $W_{f}$ is equal to the co-energy $W_{c}$.

The change in mechanical energy in a rotational system delivering mechanical power is given as:

$$
d W_{m}=T_{e m} d \theta_{r m}
$$

Where $\mathrm{T}_{\mathrm{em}}$ is electromagnetic torque and $\theta_{r m}$ is the actual angular displacement of the rotor. The flux linkages, currents, $W_{f}$ and $W_{c}$ are all expressed as a function of the electrical angular displacement $\theta_{r}$.

$$
\theta_{r}=\left(\frac{P}{2}\right) \theta_{r m}
$$

Substituting Equation (90) into Equation (89) yields:

$$
d W_{m}=T_{e m} \frac{2}{P} d \theta_{r}
$$

Because $W_{f}=W_{c}$ the electromagnetic torque can be evaluated with: 


$$
T_{e m}\left(i_{j}, \theta_{r}\right)=\frac{P}{2} \frac{\partial W_{c\left(i_{j}, \theta_{r}\right)}}{\partial \theta_{r}}
$$

Substituting Equation (88) into Equation (92) gives the electromagnetic torque of the stator side as

$$
\frac{P}{2} i_{S}^{T} \frac{\partial\left[L_{s s}\right]}{\partial \theta_{r}} i s
$$

Where,

$$
\begin{gathered}
i_{s}=\left[\begin{array}{cc}
\text { iabcs } & \text { ixyzs }
\end{array}\right] \\
L_{s}=\left[\begin{array}{cc}
L_{a b c s} & L_{\text {abcxyzs }} \\
L_{x y z a b c s} & L_{x y z s}
\end{array}\right] \\
L_{s s}=\left(L_{s}-L_{l s}\right)
\end{gathered}
$$

Substituting Equation (95) into Equation (93) gives the torque for each of the stator currents.

$$
\begin{gathered}
T_{e m}=\frac{P}{2}\left\langle(\quad \text { iabcs })^{T} \frac{\partial\left[L_{a b c s}\right]}{\partial \theta_{r}} \quad i a b c s\right. \\
+(\quad i a b c s)^{T} \frac{\partial\left[L_{a b c x y z s}\right]}{\partial \theta_{r}} \quad i x y z s+(\quad i x y z s)^{T} \frac{\partial\left[L_{x y z s}\right]}{\partial \theta_{r}} \quad i x y z s+ \\
\left.+(\quad i x y z s)^{T} \frac{\partial\left[L_{x y z a b c s}\right]}{\partial \theta_{r}} \quad i a b c s\right\rangle
\end{gathered}
$$

Applying the transformation from ' $a b c^{\prime}$ to ' $d q 0^{\prime}$ yields the torque equation:

$$
T_{e m}=\frac{3}{2} \frac{P}{2}\left(\lambda_{d 1 s} i_{q 1 s}-\lambda_{q 1 s} i_{d 1 s}+\lambda_{d 2 s} i_{q 1 s}-\lambda_{q 2 s} i_{d 2 s}\right)
$$

\subsection{Equivalent circuit}

The electrical system of this machine as described by Equations (80)\&(84)-(87) can be represented with an equivalent circuit. The zero sequence circuit diagram is omitted because the system is assumed to be balanced.
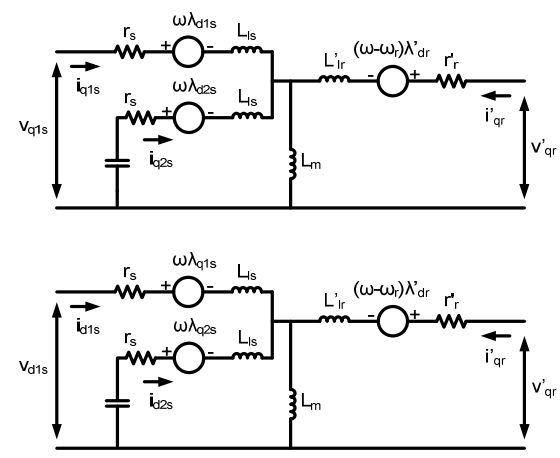

Figure 5. Equivalent ' $q d$ ' circuit diagrams 


\section{Simulation results}

The derived mathematical models implemented in the Matlab/Simulink environment can be used to generate steady-state and dynamic simulation results. The machine without compensation is used as reference. Capacitance is added to the auxiliary winding and compared with the behaviour of the reference machine. This will show the effect of the capacitors connected to the auxiliary winding on the performance of the modified machine. The dynamic model can be used for steady state analysis by taking readings after the transient.

\subsection{Steady state analysis}

The main objective of the modifications done in terms of the addition of the auxiliary winding is to improve the poor power factor an induction motor has. It is therefore important to focus on the behaviour of the machine parameters that involves power factor when introducing reactive power injection.

Figure 6 shows that the injection of reactive power in the auxiliary winding improves the power factor of the motor. The bigger the size of the capacitor, the more reactive power is injected and hence the better the power factor. For this specific machine, capacitors of $30 \mu \mathrm{F}$ connected per phase as in Figure 4 leads to a power factor very close to unity.

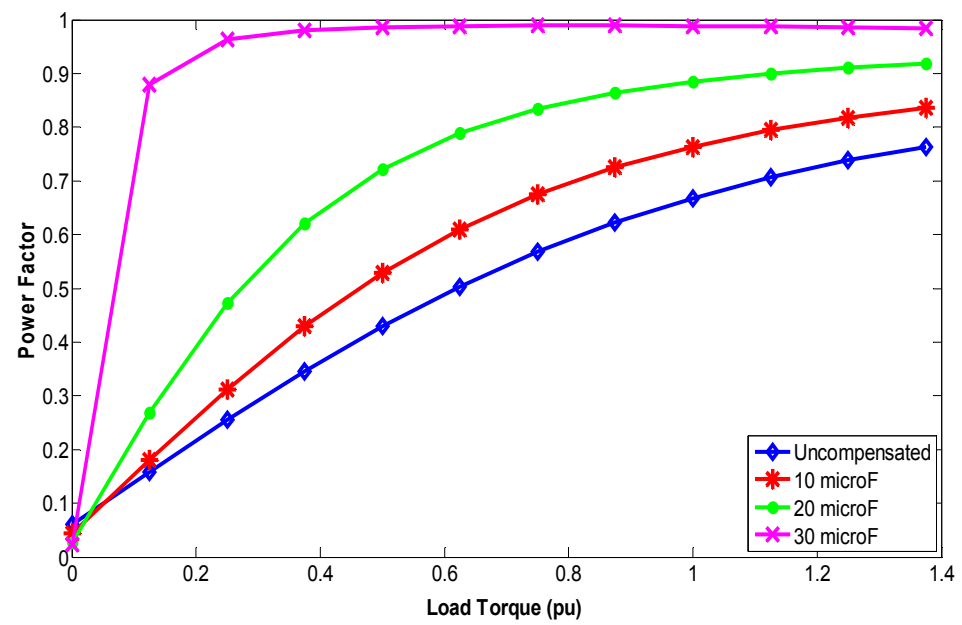

Figure 6. Torque - Power Factor waveform 


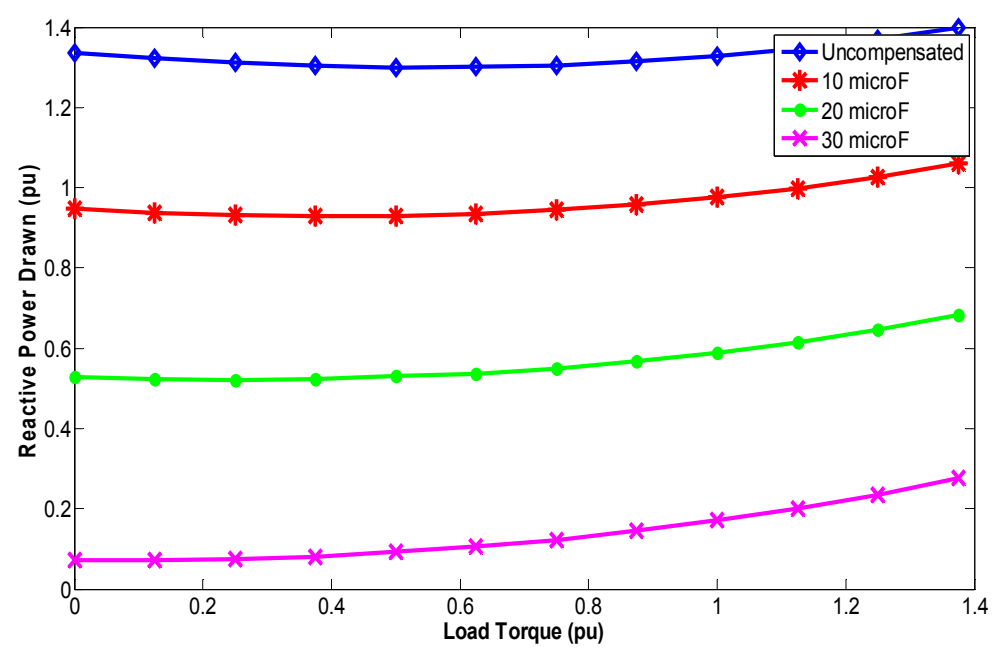

Figure 7. Torque - Reactive Power waveform

With the increase in power factor as seen in Figure 6 it is expected that less reactive power will be drawn from the source with the addition of capacitors to the auxiliary winding. Figure 7 supports this expectation. In Figure 7 the reactive power drawn from the source reduces with increasing capacitor size.

Because the reactive component of the supply current decreases with the reactive power injection, the magnitude of the supply current therefore decreases. This is shown in Figure 8.

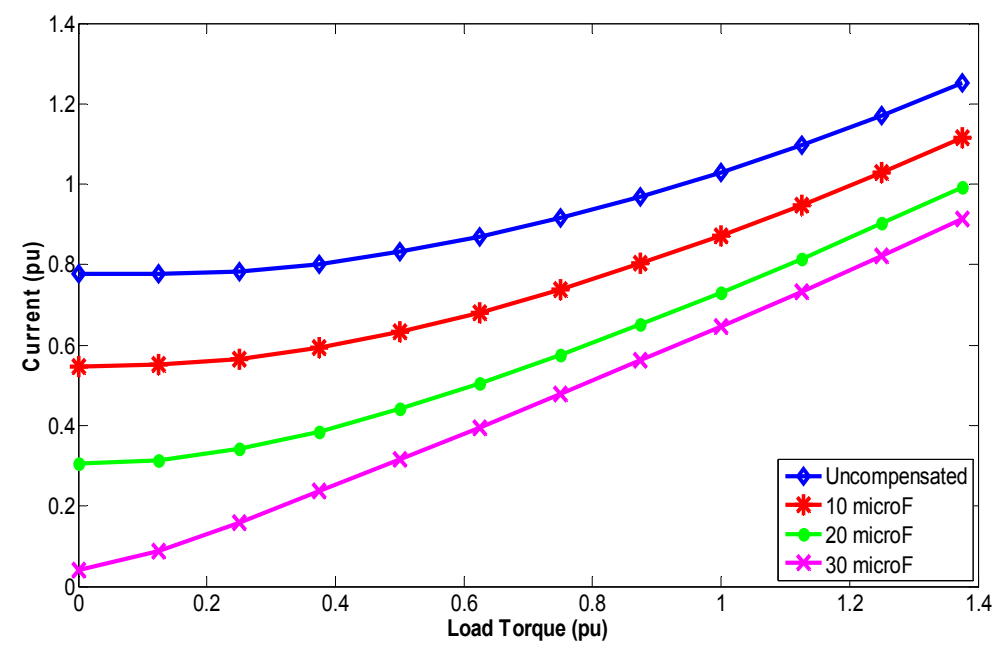

Figure 8. Torque-Current waveform 


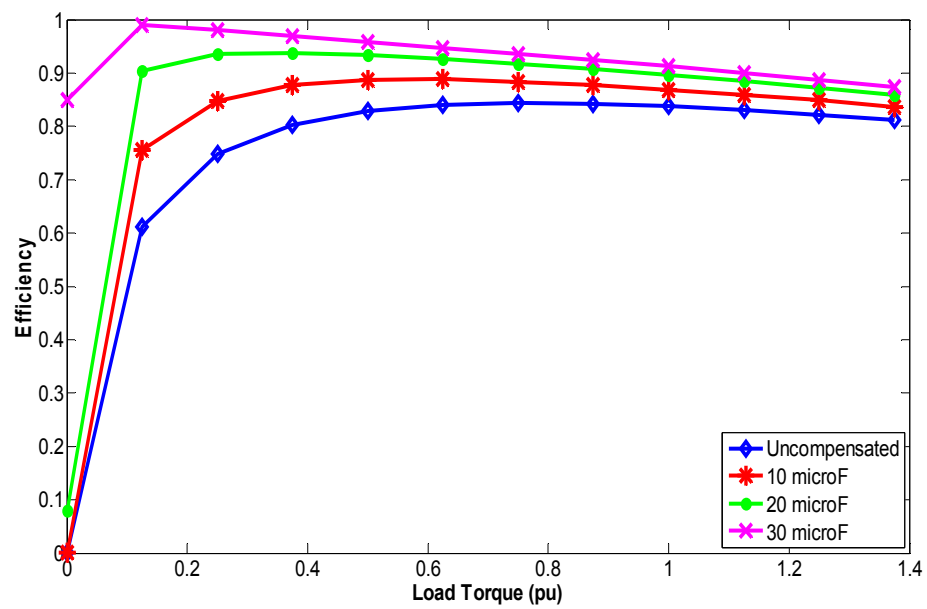

Figure 9. Torque Efficiency waveform

The active power drawn from the source consists of different components of which one is copper losses ( $I^{2} \mathrm{R}$ losses). With the decrease of current shown in Figure 8, it is logical that the copper losses of the main stator winding will also decrease. This will lead to a decrease in active power drawn from the source without a change in output power and hence the improvement in the efficiency of the motor as seen in Figure 9.

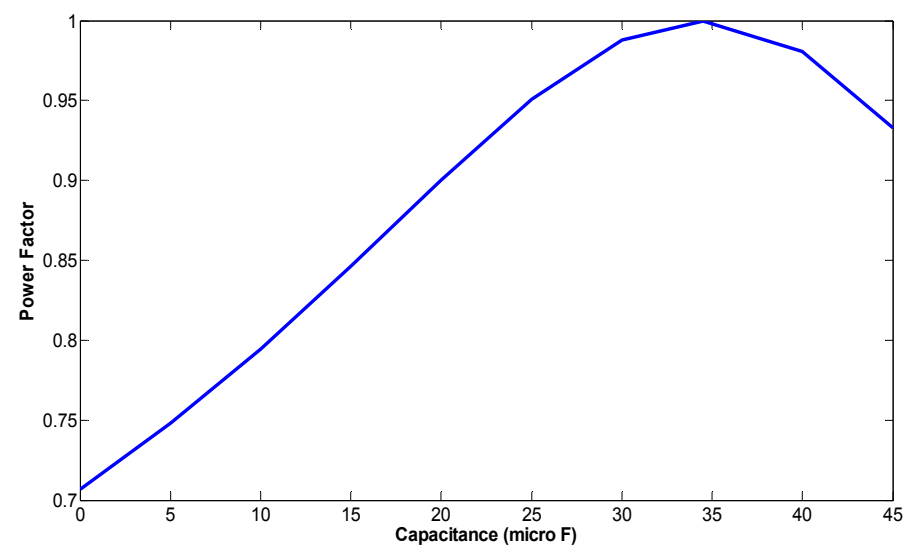

Figure 10. Capacitance-Power Factor waveform 


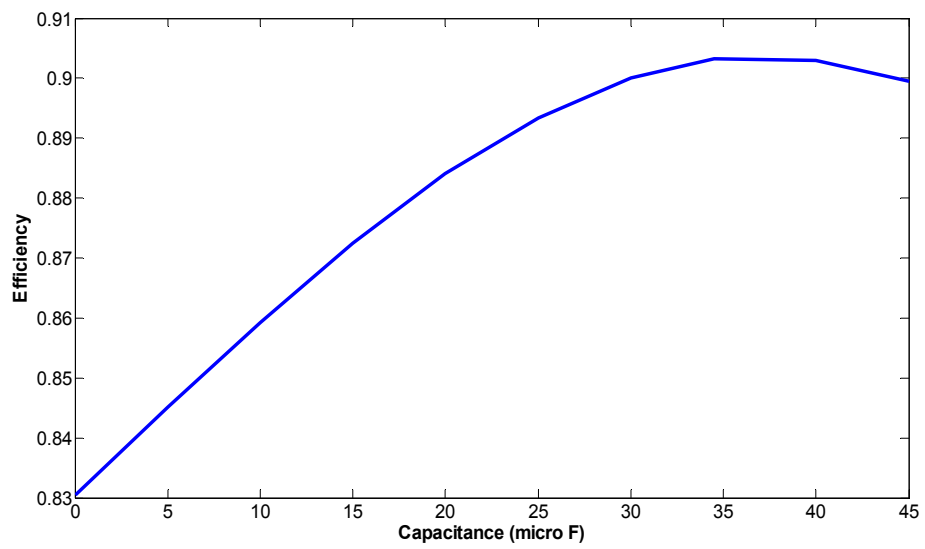

Figure 11. Capacitance-Efficiency waveform

The effect that the change of capacitance has on the performance of the machine is studied in Figures 10 and 11. Figure 10 shows that as the capacitance increase the power factor also increases. It also shows that it is possible to over-compensate the machine which will lead to a decreasing power factor. With the current machine at the current load it can be seen that the optimum value for the capacitor is slightly less than $35 \mu \mathrm{F}$ and will lead to a power factor close to unity. Figure 11 shows the improvement in efficiency as capacitance increases. The efficiency of this machine at current load can be improved with about 0.07 as seen in Figure 11.

\subsection{Dynamic analysis}

Steady-state analysis is not always sufficient in determining the behaviour of an electrical machine. Transient and dynamic periods are the most likely periods for harming an electrical machine. The dynamic model will show the exact behaviour of the machine during transient and or dynamic periods.

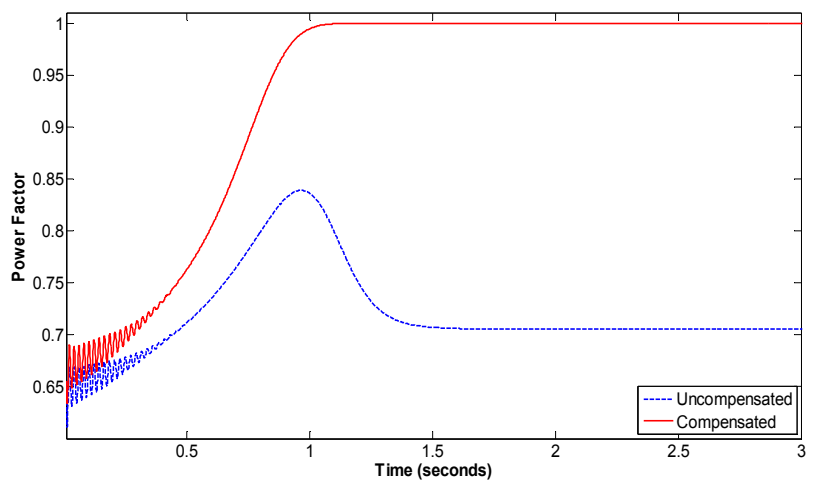

Figure 12. Power Factor 


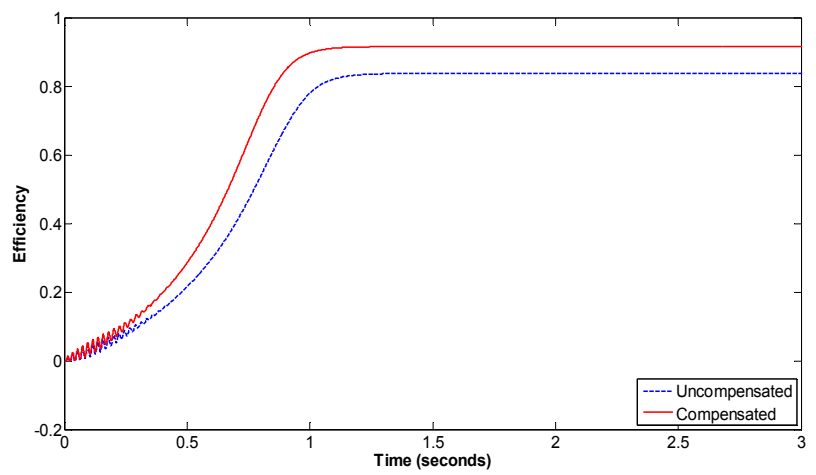

Figure 13. Efficiency

The dynamic behaviour of a compensated and uncompensated induction machine is compared in Figure 12. The uncompensated machine (dashed waveform) has a low power factor when starting and settles at a power factor of just more than 0.7. The compensated machine (solid waveform) has a higher power factor when starting and settles at a power factor close to unity. This shows how effective this concept is in power factor correction.

The earlier statement that the improvement in power factor will improve the efficiency is supported in Figure 13.

The inrush current of the machine is shown in Figure 14. This machine has a transient state when starting where the current can reach eight times rated current.

The current of the auxiliary winding is shown in Figure 15.
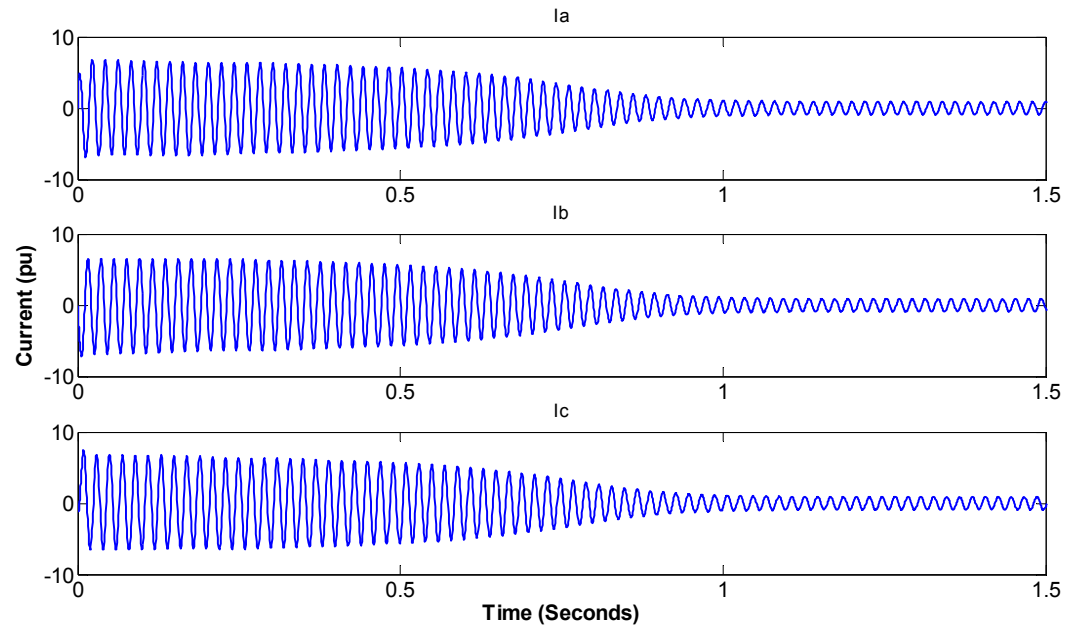

Figure 14. Phase Currents - Main Stator Winding 

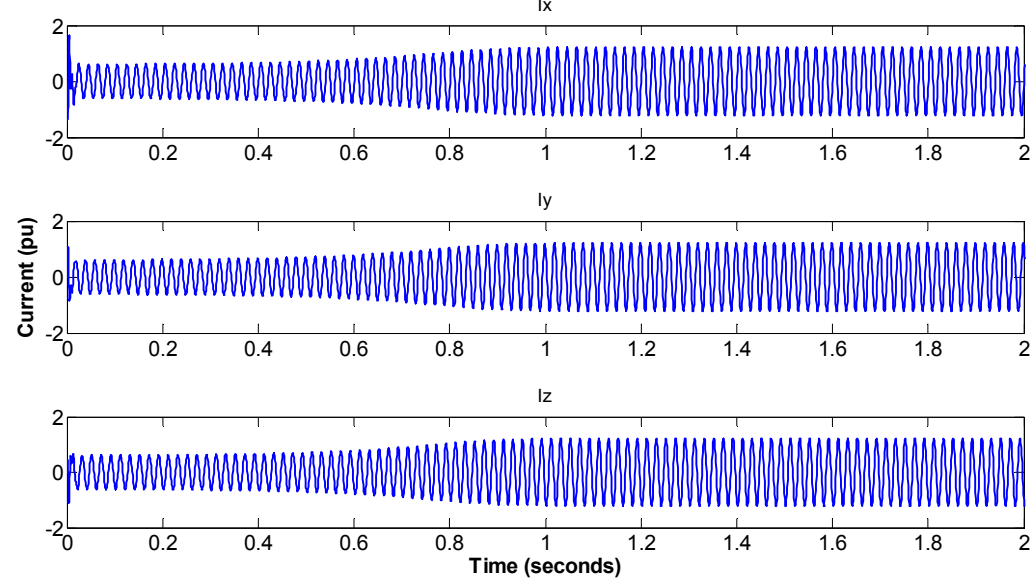

Figure 15. Phase Currents - Auxiliary Stator Winding

\section{Experimental validation}

In order to validate the theoretical model with the practical model, three capacitor values of 10,20 and $30 \mu \mathrm{F}$ are used for the three phase auxiliary winding.

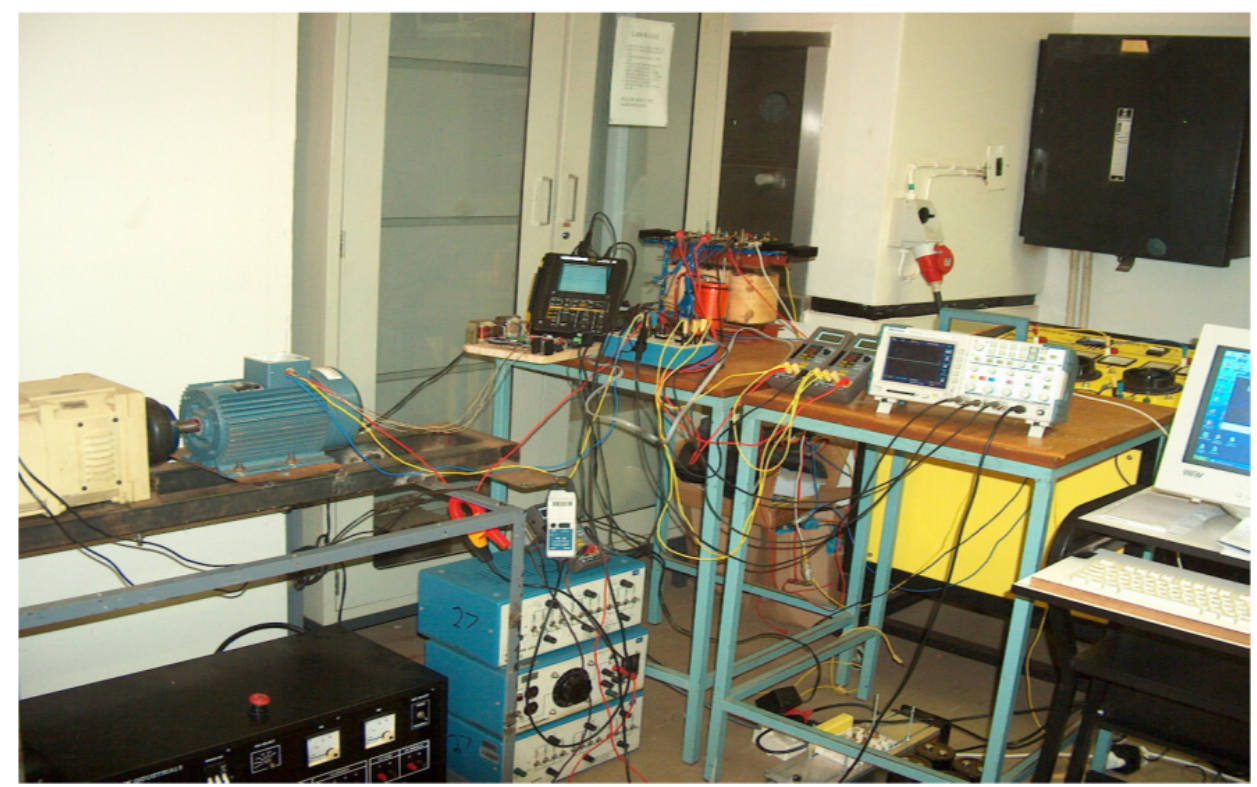

Figure 16. The Experimental set up 
The stator current of the motor is observed for both uncompensated and compensated windings. It is seen that the starting current for the uncompensated winding is high as compared to the compensated. The current at steady state also identifies the stator current for the uncompensated to be lower as compared to the compensated. These results are shown in figures 17 and 18.

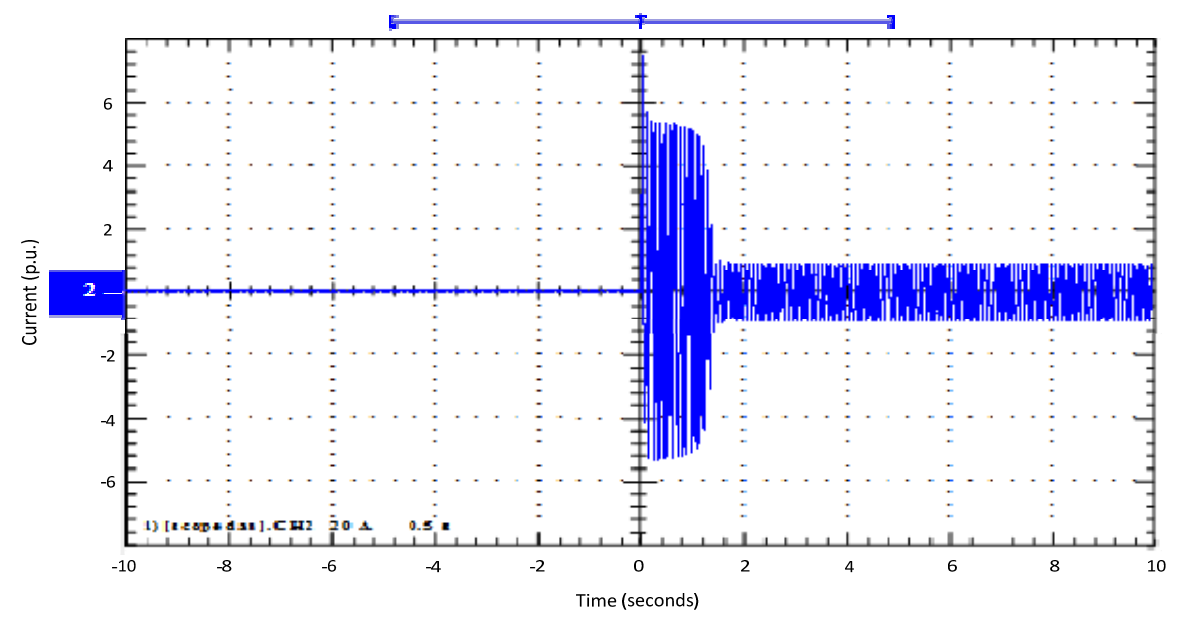

Figure 17. Stator current of uncompensated winding

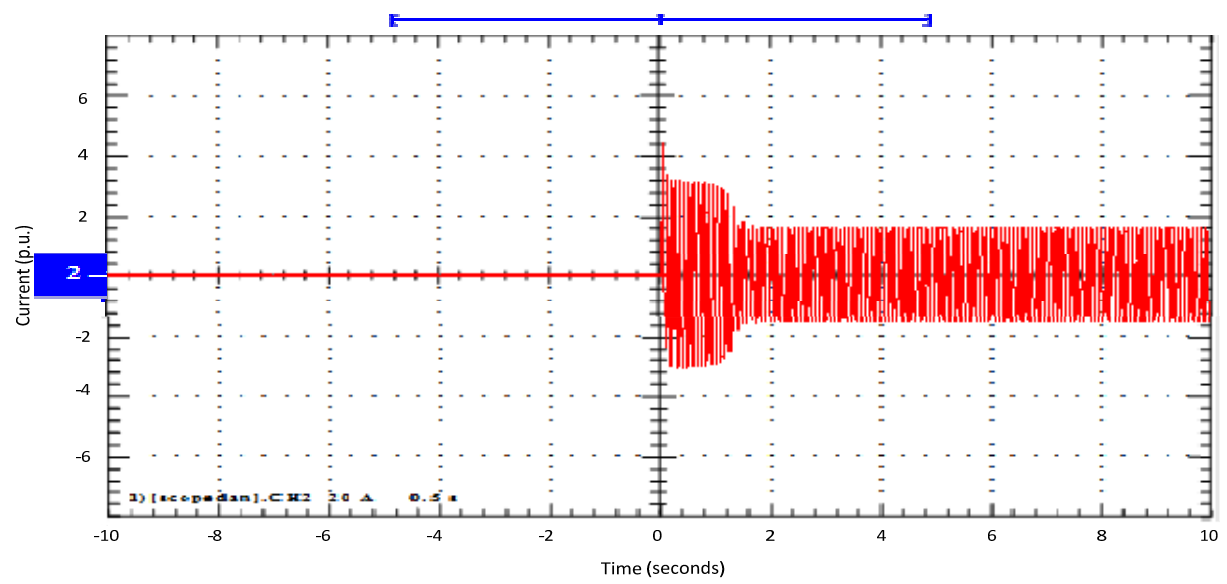

Figure 18. Phase Currents-Stator current of the compensated winding

Other experimental results such as the active power versus the capacitance and power factor versus capacitance are shown in figure 19. These results conform to the theoretical simulations. 

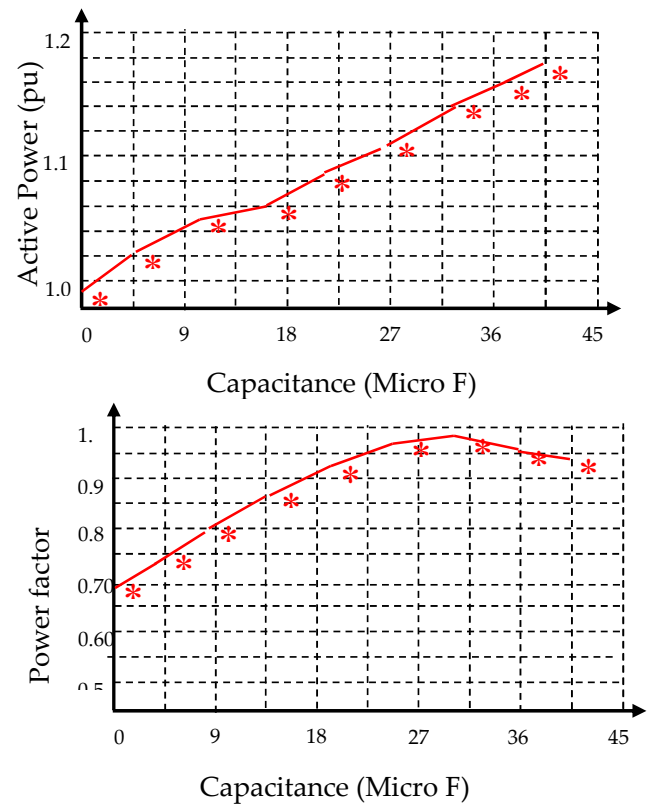

Figure 19. Experimental results of active power and power factor versus capacitance values
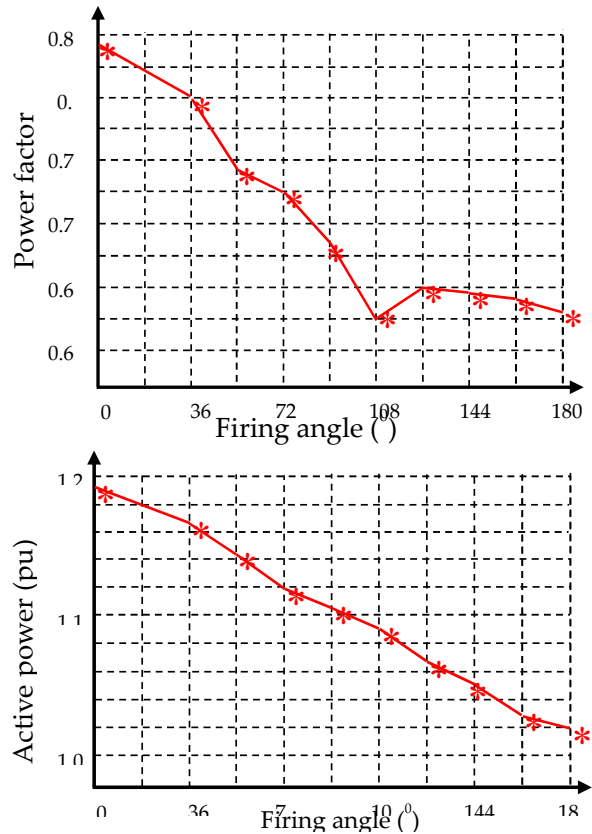

Figure 20. Experimental results of power factor and active power versus firing angle 


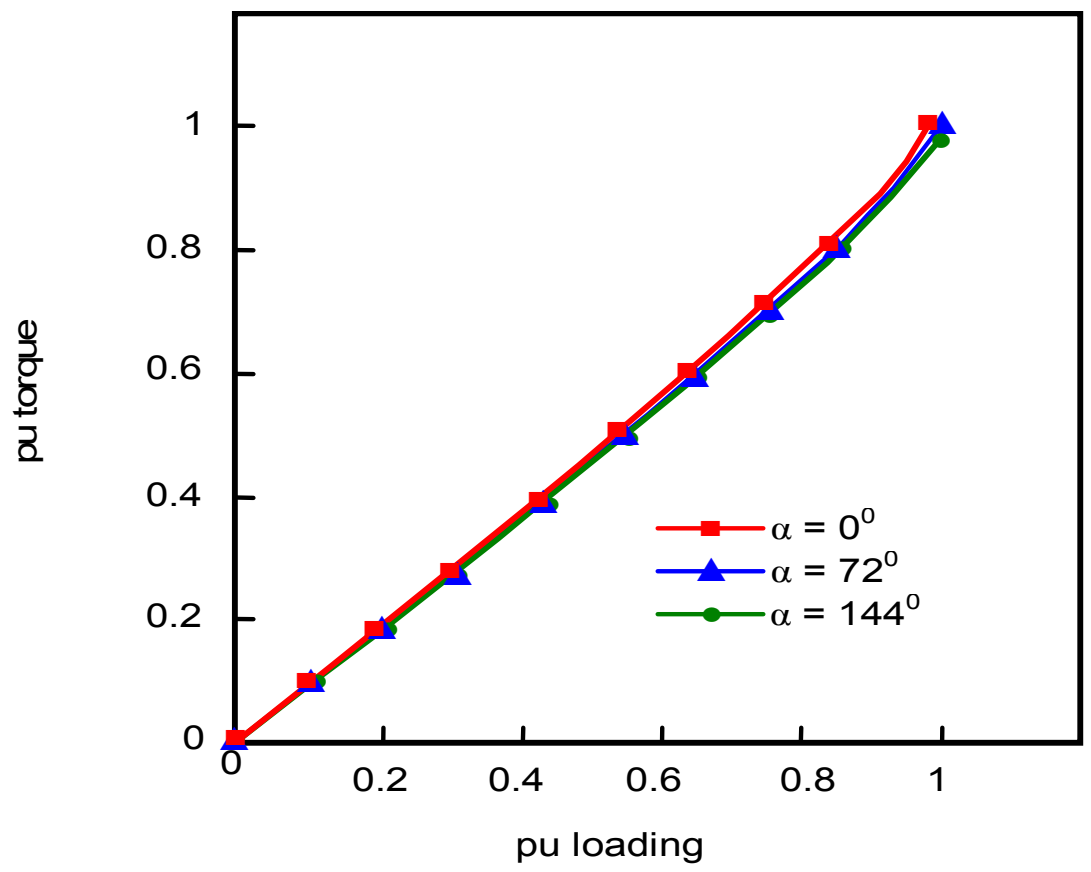

Figure 21. A p.u plot of torque versus p.u. loading for various angles

Since the effective capacitance varies with load when there is an application with varying load, the machine might not always operate at optimum power factor. A possible solution to this is to implement a thyristor controlled static switch or a PWM controller between the capacitors and the auxiliary winding; this will make the capacitance and therefore power factor controllable. Finally, further experiment is carried out on the active power per phase, the power factor versus firing angle and the per unit torque versus per unit loading where the switched series capacitor is connected to the auxiliary winding. The static switching is such that only the required level of reactive compensation is allowed. Figures 20 and 21 are the experimental results obtained based on this analysis.

\section{Conclusion}

A study has been conducted on a $0.75 \mathrm{KW}$ machine with $380 \mathrm{~V}, 50 \mathrm{~Hz}$ supply for an effective power factor correction. This has been achieved by connecting the main winding to the three phase supply and the auxiliary winding to the fixed capacitors for reactive power injection. The modified machine with reactive power injection has potential compared to the conventional three-phase machines. It is seen from the waveform analysis that the machine has capability of reducing the starting current. Simulation results have shown a good improvement on both power factor and efficiency when introducing the reactive power injection with increase of capacitor value. Both steady-state and dynamic analysis together 
with experimental set up has shown a great improvement compared to the uncompensated machine. Another very important improvement is the supply current decreasing with increasing capacitance. This is not the case with conventional power factor correction techniques because the reactive power needed is still drawn through the only stator winding set. This advantage of the modified machine may potentially reduce installation costs as smaller supply cables can be used.

Despite its good performance it has certain drawbacks. The machine would be bigger in structure than a conventional machine. More copper is needed for the additional winding and more insulating material is needed. This would make the machine much more expensive than the conventional three phase machine. Another drawback of this concept is that the capacitors have to be sized for a specific load. When there is an application with varying load, the machine might not always operate at optimum power factor. A possible solution to this is to implement a PWM controller between the capacitors and the auxiliary winding; this will make the capacitance and therefore power factor controllable.

This modified induction machine has a research potential with the recent focus on energy efficiency. Further research needs to be carried out on the performance behaviour of this machine.

\section{Author details}

Adisa A. Jimoh, Pierre-Jac Venter and Edward K. Appiah

Tshwane University of Technology, Pretoria, South Africa

\section{References}

el-Sharkawi, M. A., Venkata, S. S., Williams, T. J. \& Butler, N. G. (1985) An Adaptive Power Factor Controller for Three-Phase Induction Generators. Power Apparatus and Systems, IEEE Transactions on, PAS-104, 1825-1831.

Jimoh, A. A. \& Nicolae, D. V. (2007) Controlled Capacitance Injection into a Three-Phase Induction Motor through a Single-Phase Auxiliary Stator Winding. Electric Machines $\mathcal{E}$ Drives Conference, 2007. IEMDC '07. IEEE International.

Krause, P. C. (1986) Analysis of Electric Machinery, New York, Mcgraw-Hill.

Lipo, T. A. \& Novotny, D. W. (1996) Vector Control and Dynamics of AC Drives. In Hammond, P., Miller, T. J. E. \& Kenjo, T. (Eds.). New York, Oxford Science Publications.

Muljadi, E., Lipo, T. A. \& Novotny, D. W. (1989) Power factor enhancement of induction machines by means of solid-state excitation. Power Electronics, IEEE Transactions on, 4, 409-418.

Park, R. H. (1929) Two-Reaction Theory of Synchronous Machines Generalized Method of Analysis-Part I. American Institute of Electrical Engineers, Transactions of the, 48, 716-727. 
Stanley, H. C. (1938) An Analysis of the Induction Machine. American Institute of Electrical Engineers, Transactions of the, 57, 751-7. 